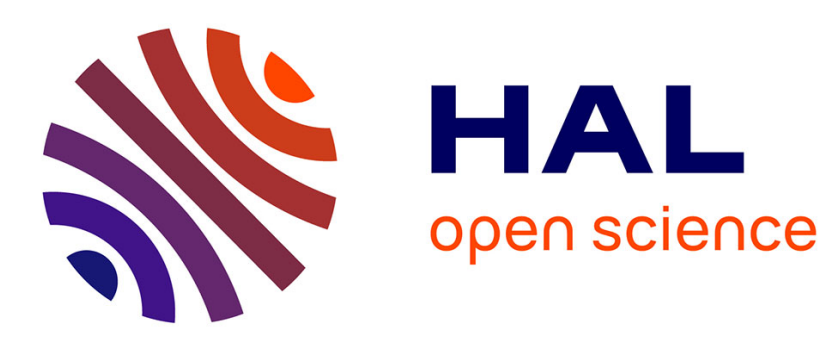

\title{
Electrochemical characterization of liquid-liquid micro-interfaces modified with mesoporous silica
}

Lukasz Poltorak, Karima Morakchi, Grégoire Herzog, Alain Walcarius

\section{To cite this version:}

Lukasz Poltorak, Karima Morakchi, Grégoire Herzog, Alain Walcarius. Electrochemical characterization of liquid-liquid micro-interfaces modified with mesoporous silica. Electrochimica Acta, 2015, 179, pp.9 - 15. 10.1016/j.electacta.2015.01.129 . hal-01498764

\section{HAL Id: hal-01498764 \\ https://hal.univ-lorraine.fr/hal-01498764}

Submitted on 9 Nov 2018

HAL is a multi-disciplinary open access archive for the deposit and dissemination of scientific research documents, whether they are published or not. The documents may come from teaching and research institutions in France or abroad, or from public or private research centers.
L'archive ouverte pluridisciplinaire HAL, est destinée au dépôt et à la diffusion de documents scientifiques de niveau recherche, publiés ou non, émanant des établissements d'enseignement et de recherche français ou étrangers, des laboratoires publics ou privés. 


\title{
Electrochemical characterization of liquid-liquid micro- interfaces modified with mesoporous silica
}

\author{
Lukasz Poltorak $^{1}$, Karima Morakchi, ${ }^{1,2}$ Grégoire Herzog $^{1 *}$, Alain Walcarius ${ }^{1}$ \\ ${ }^{1}$ Laboratoire de Chimie Physique et Microbiologie pour l'Environnement, (LCPME) UMR \\ 7564, CNRS - Université de Lorraine, 405 rue de Vandoeuvre, 54600 Villers-les-Nancy, \\ France. \\ ${ }^{2}$ Laboratoire de Recherche Génie de l'Environnement, Faculté des Sciences de l'Ingénieur, \\ Annaba BP 12, Algeria \\ *gregoire.herzog@univ-lorraine.fr
}

Keywords: ion-transfer voltammetry, PAMAM dendrimers, tetraalkylammonium cations, 4octyl benzene sulfonate, ITIES, surfactant template.

This document is a postprint. Final version has been published in Electrochimica Acta, 2015, 179, 915 (https://doi.org/10.1016/i.electacta.2015.01.129).

\begin{abstract}
In this work, the array of miniaturized interfaces between two immiscible electrolyte solutions was modified with a mesoporous silica material. The electrochemical behavior of such silica deposits was evaluated with six analytes: 3 tetraalkylammonium cations of different sizes, the anionic 4octylbenzenesulfonate and two poly(aminoamide) dendrimers (generation 0 and 1). Presence of silica deposits affects the ion transfer across the liquid/liquid interface for all six probes with the effect greater for species possessing higher hydrodynamic radius. Analytical parameters (sensitivity and detection limit) were extracted from the calibration curves plotted in the presence and in the absence of silica deposits. Results indicate that silica constitutes an obstacle for interfacial transfer reaction and becomes limiting factor for interfacial mass transfer. Three main conclusions can be drawn from the experimental observations: (i) for tetraalkylammonium species, the larger species (tetrabutylammonium) is more affected by the presence of silica deposits than the smaller species (tetramethylammonium); (ii) due to the negative charge of silica walls, anions are more affected than cations of the same size; (iii) multiply charged cationic dendrimers are less affected by the presence of silica deposits than smaller single charge cations. Apparent diffusion coefficients for all species were also extracted from calibration curves plotted after modification.
\end{abstract}




\section{Introduction}

The interface between two immiscible electrolyte solutions (ITIES) as an electrochemical sensor is basically deprived of mechanical defects, it can be self-healing and it enables the detection of hydrophobic and hydrophilic species. Furthermore, the liquid/liquid interface can be miniaturized down to the micro- and nanoscale level [1-3], which improves the sensitivity (due to enhanced mass transport) and lowers the limit of detection (due to smaller capacitive currents). Both sensitivity and limit of detection are qualitative parameters indicative of a good analytical detection method. The range of ionic analytes detectable at the ITIES is broad, examples include: inorganic molecules - alkali metals [4]; small organic molecules drugs [5], food additives [6]; synthetic and natural macromolecules - dendrimers [7-9], polyelectrolytes [10,11] and protein [12-14], or species of biological importance $[15,16]$. Despite this broad range of targets, selectivity of the ITIES remains to be improved. Two approaches are taken to improve the selectivity of the ITIES. The first one concerns the use of selective ionophores to favor the assisted transfer of ions [17], whereas the second approach deals with the ex-situ ITIES modification (with zeolite molecular sieve [18]).

In conventional electrochemical techniques - with working electrode being the solid conductor - weak selectivity is frequently solved via surface modification [19]. In this context, great attention was paid to mesoporous silica modifiers as they can be easily deposited onto solid substrate [20], they exhibit a high specific surface area and ordered threedimensional structures [21] with chemical functionalities [22] can be formed. Under the suitable conditions, the formation of ordered and oriented mesoporous silica materials can be controlled. A method called 'electro-assisted self-assembly' employing a sol-gel process based on a surfactant template allows the formation of mesoporous silica with highly ordered symmetry of pores oriented perpendicular to the electrode surface [23,24]. In addition, choosing the suitable template allows the tuning of the pore sizes among the silica framework [25], which is of greatest interest for sensing devices. Template-based mesoporous silica found numerous applications: as immobilization host for biologically active molecules [26], in membrane separation processes [27], as templates in nanocasting formation of array of nanowires [28], in drug delivery [29] and finally in electroanalytical chemistry [30,31] and sensing [32]. In our previous works, we have shown that a sol-gel process based on a surfactant template can be easily performed at the macroscopic ITIES with the help of ion transfer voltammetry [33]. This requires the presence of hydrolyzed silica present in the aqueous phase and cationic surfactant - cetyltrimethylammonium cations $\left(\mathrm{CTA}^{+}\right)-$in the 
organic phase. The interfacial polarization leads to the transfer of $C T A_{\text {org }}^{+}$to the aqueous phase and an interfacial silica deposit is formed upon self-assembly condensation. Subsequently, the protocol developed at macroITIES was adapted to the array of microITIES supported by silicon wafer [33]. Miniaturization provides good mechanical stability of electrogenerated free standing silica deposits and gives better electro-analytical response [34]. The mechanism for the formation of silica deposits was proposed based on electrochemical, Raman spectroscopy and electron microscopy studies [33-35].

Here, to go one step further, an array of liquid-liquid micro-interfaces was modified with silica deposits formed around a $\mathrm{CTA}^{+}$template and then characterized by ion transfer voltammetry of six different model ions: three cations from the tetralkylammonium family (tetramethylammonium $\mathrm{TMA}^{+}$, tetraethylammonium $\mathrm{TEA}^{+}$and tetrabutylammonium $\mathrm{TBA}^{+}$), one anion (4-octylbenzenesulfonate, 4OBSA${ }^{-}$), and two dendritic cations from the poly(aminoamide) dendrimer family (PAMAM generation G0 and G1). These ions differ in size, charge and chemical nature. The ion transfer potential and currents of these six ions before and after modification of the ITIES with mesoporous silica were compared. We investigate the influence of the ions characteristics (charge, $z_{i}$, diffusion coefficient, $D$ and molecular hydrodynamic radius $r_{h}$ ) on analytical parameters such as sensitivity, limit of detection and apparent diffusion coefficient, and how the interface modification affected those characteristics.

\section{Experimental}

\subsection{Chemicals}

Bis(triphenylphosphoranyldiene) ammonium chloride, $\left(\mathrm{BTPPA}^{+} \mathrm{Cl}^{-}, 97 \%\right.$, Aldrich) and potassium tetrakis(4-chlorophenylborate), $\left(\mathrm{K}^{+} \mathrm{TPBCl}^{-}, \geq 98 \%\right.$, Fluka), were used to prepare the organic electrolyte by metathesis reaction. Sodium chloride, $(\mathrm{NaCl}, \geq 98 \%$, Prolabo) and lithium chloride ( $\mathrm{LiCl}, \geq 99 \%$, Aldrich) were used as the aqueous phase electrolytes. Cetyltrimethylammonium bromide (CTAB, $\geq 99 \%$, Acros Organics) and $\mathrm{K}^{+} \mathrm{TPBCl}^{-}$were used for the preparation of template salt by metathesis reaction [33]. Silica precursor used in this study was tetraethoxysilane (TEOS, 98\%, Alfa Aesar). The $\mathrm{pH}$ of the aqueous phase during hydrolysis $(\mathrm{pH}=3)$ and condensation $(\mathrm{pH}=9.5)$ of TEOS was adjusted with solutions of $1 \mathrm{M}$ $\mathrm{HCl}$ (1M, volumetric solution, Riedel-de Haen) and $1 \mathrm{M} \mathrm{NaOH}$ (from pellets, pure, Riedel-de Haen). Tetramethylammonium chloride $\left(\mathrm{TMA}^{+} \mathrm{Cl}^{-}, \geq 99 \%\right.$, Fluka), tetraethylammonium 
chloride ( $\mathrm{TEA}^{+} \mathrm{Cl}^{-}, \geq 99 \%$, Fluka), tetrabuthylammonium chloride $\left(\mathrm{TBA}^{+} \mathrm{Cl}^{-}, \geq 99 \%\right.$, Fluka), 4octylbenzenesulfonic acid sodium salt (4OBSA`, 97\%, Fluka), poly(aminoamide) generation 0 (PAMAM G0, 20\% solution in methanol, Aldrich) and poly(aminoamide) generation 1 (PAMAM G1, 20\% solution in methanol, Aldrich) were employed for electrochemical characterization of silica material-modified liquid/liquid interface. The high density organic phase was a 1.2-dichloroethane (DCE, $\geq 99 \%$, Sigma-Aldrich) whereas the low density phase was high purity $\mathrm{H}_{2} \mathrm{O}$ obtained from a Millipore milli-Q water purification system. Ferric chloride hexahydrate $\left(\mathrm{FeCl}_{3} \cdot 6 \mathrm{H}_{2} \mathrm{O}, 99-102 \%\right.$, Fluka) was used to prepare silver/silver chloride reference electrodes.

\subsection{Electrochemical cell}

The electrochemical cell used in this work is the same as used previously [34]. The platinum mesh and a silver/silver chloride wire were used as aqueous counter and reference electrodes respectively. Organic phase was placed into the capillary to the end of which silicon wafer supporting the array of ITIES was attached. Wafer was fixed with Rubson® silicone acetate sealant. A silver / silver chloride wire spiral acted as both reference and counter electrodes for the organic phase. The $\mu$ ITIES array were patterned by photolithography and pierced by a combination of deep ion reactive and wet etches as described elsewhere [36]. A $\mu$ ITIES array was made of 30 pores of $5 \mu \mathrm{m}$ radius separated by $200 \mu \mathrm{m}$. All electrochemical experiments were run with a PGSTAT 302N from Autolab (Metrohm, Switzerland), with a four electrode set-up (Scheme 1).

\subsection{Interfacial silica electrodeposition and ion-transfer study}

Two electrochemical cell configurations were used (Scheme 1), one for the silica deposition (cell 1) and the other one for electrochemical characterization of the modified $\mu$ ITIES by ion transfer voltammetry (cell 2).

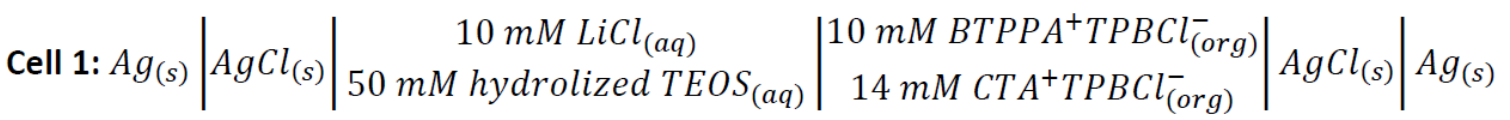

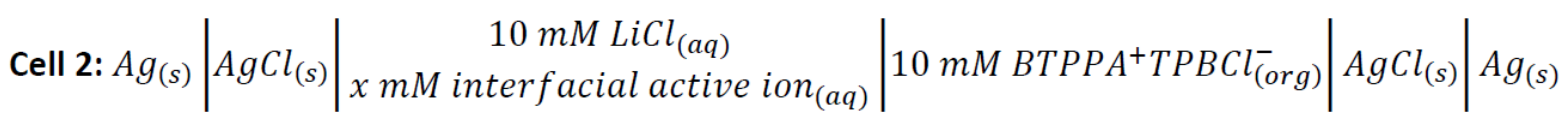

Scheme 1. Electrochemical cells for silica electrodeposition (cell 1) and interfacial ions transfer study (cell 2). 
Silica material at liquid/liquid interface was electrodeposited by cyclic voltammetry (Figure 1) at $5 \mathrm{mV} \mathrm{s}^{-1}$ using electrochemical cell 1 . On the forward scan, $\mathrm{CTA}^{+}$ions are transferred from the organic to the aqueous phase, which triggered the condensation of silica. On the reverse scan, $\mathrm{CTA}^{+}$adsorbed on the silica deposited are transferred back to the organic phase through a non-diffusion controlled process [34]. Aqueous and organic phases were then removed, carefully rinsed with water and placed in an oven at $130^{\circ} \mathrm{C}$ for 16 hours in order to achieve condensation of the silica network. Organic electrolyte and template molecules trapped in the porous silica network were then removed by calcination at $450^{\circ} \mathrm{C}$ for 30 minutes. The modified $\mu$ ITIES array was then ready for electrochemical characterization (performed in cell 2 on scheme 1). The deposit morphology was observed by scanning electron microscopy using a Phillips XL30 Microscope (with acceleration voltage of $1 \mathrm{kV}$ ) without any sample metallization, and by transmission electron microscopy using a Philips CM20 microscope at an acceleration voltage of $200 \mathrm{kV}$. Scanning electron micrographs inform us that the silica is deposited on the aqueous side of the interface and it is of hemispherical shape. Transmission electron micrographs confirm a worm-like mesoporous structure as it was observed at macroscopic liquid-liquid interfaces [33].
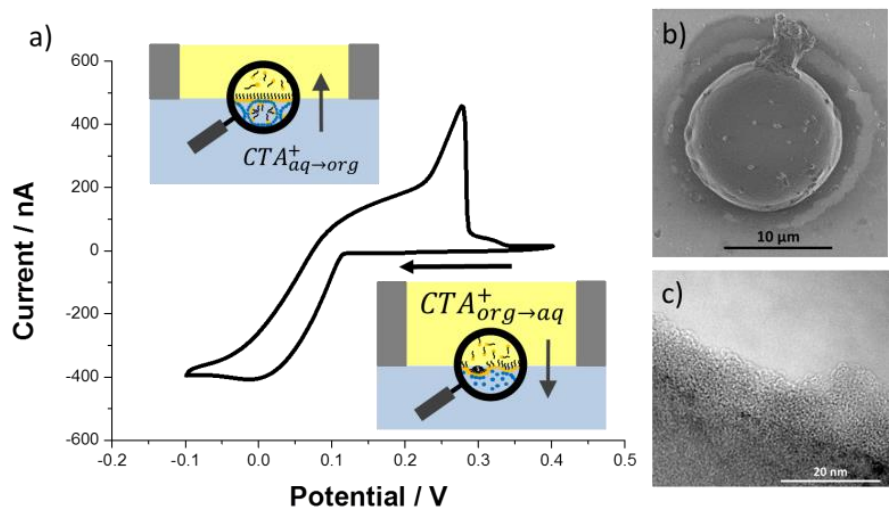

Figure 1. a) Typical cyclic voltammogram recorded during silica electrodeposition at an array of miniaturized ITIES. The arrow indicates the scan direction. Concentration of $\mathrm{CTA}^{+}=14$ $\mathrm{mM}$ and TEOS $=50 \mathrm{mM}$, scan rate $=5 \mathrm{mV} \mathrm{s}^{-1} \mathrm{~b}$ ) Top-view scanning electron micrograph of a single modified pore and c) Transmission electron micrograph of mesoporous silica.

\section{Results and discussion}

\subsection{Blank cyclic voltammetry before and after modification}


Figure 2 shows the blank CVs recorded before and after modification of the $\mu$ ITIES array. The potential region was scanned from more negative to more positive potentials. The potential window was determined by the transfer of the electrolyte ions dissolved in each phase, which resulted in a current rise. There is no significant impact of the presence of the silica deposited at the interface on the potential window. At the negative end, the potential window is limited by the transfer of $\mathrm{Cl}^{-}$, which occurs at a higher potential than $\mathrm{BTPPA}^{+}$ions. Indeed, previous studies have shown that the Galvani potential for $\mathrm{Cl}^{-}$is $\Delta \Phi^{1 / 2}=-0.53 \mathrm{~V}$ [37,38], whereas the Galvani potential for $\mathrm{BTPPA}^{+}$is $\Delta \Phi^{1 / 2}=-0.70 \mathrm{~V}$ [37]. The peak observed at $\Delta \Phi=-0.45 \mathrm{~V}$ was then attributed to the back-transfer of $\mathrm{Cl}^{-}$from organic to aqueous, whose diffusion was confined inside the $\mu$ ITIES pores and hence was linear. At the positive end of the potential window, the transfer is limited by the transfer of $\mathrm{Li}^{+}$. The potential window of a blank CV at a bare ITIES is larger in the absence than in the presence of aqueous electrolyte. Unfortunately, the Galvani standard potential for the transfer of $\mathrm{TPBCl}^{-}$has never been determined [37] and we can only assume that it is lower than the one for $\mathrm{Li}^{+}, \Delta \Phi^{1 / 2}=+0.58 \mathrm{~V}$ [39]. Blank CVs in the absence of aqueous electrolyte at bare and modified ITIES showed that the presence of silica at the interface impedes the transfer of large organic ions (Inset of Figure 2).

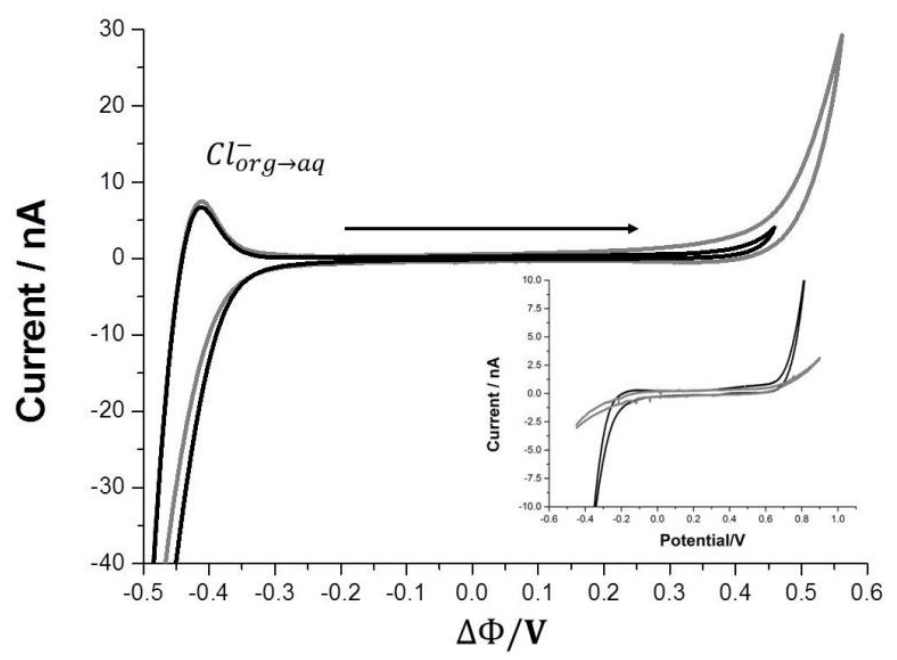

Figure 2. Blank CV recorded before (black line) and after (gray line) modification. Black arrow indicates the direction of the forward scan. Scan rate was $10 \mathrm{mV} \mathrm{s}^{-1}$. Inset: Blank CV in the absence of aqueous electrolyte recorded before (black line) and after (gray line) modification.

\subsection{Cyclic voltammetry of single charge ions before and after modification}


Figure 3 shows the cyclic voltammograms (CV) of three tetraalkylammonium cations of different sizes $\left(\mathrm{TMA}^{+}, \mathrm{TEA}^{+}\right.$and $\left.\mathrm{TBA}^{+}\right)$- Fig. $3 \mathrm{a}-$ and of the negatively charged 4OBSA ${ }^{-}-$ Fig. 3 b. The electrochemical behavior of each analyte was investigated before and after $\mu$ ITIES modification. All ions were initially present in the aqueous phase at the concentration of $56.8 \mu \mathrm{M}$, and the forward polarization was selected in agreement with the charge of transferring species (towards positive potentials for tetraalkylammonium cations and towards negative potentials for $4 \mathrm{OBSA}^{-}$). The shape of cyclic voltammograms for all species showed a sigmoidal forward signal - being in agreement with hemispherical diffusion zone from aqueous side of interface - and a reverse peak response - indicative of linear diffusion limitation inside the $\mu$ ITIES pore channels filled with the organic phase. The voltammograms are shown on the Galvani potential scale, based on the peak transfer of $\mathrm{Cl}^{-}$.

a)

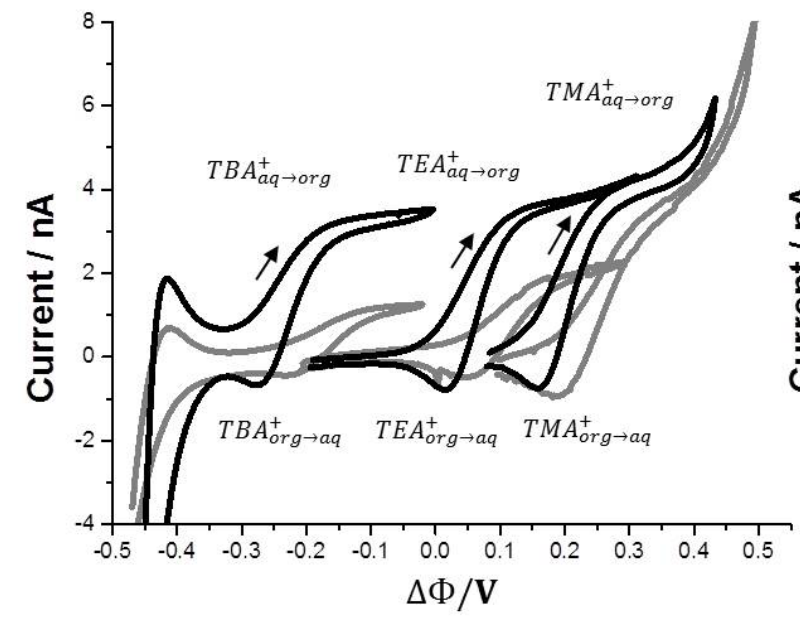

b)

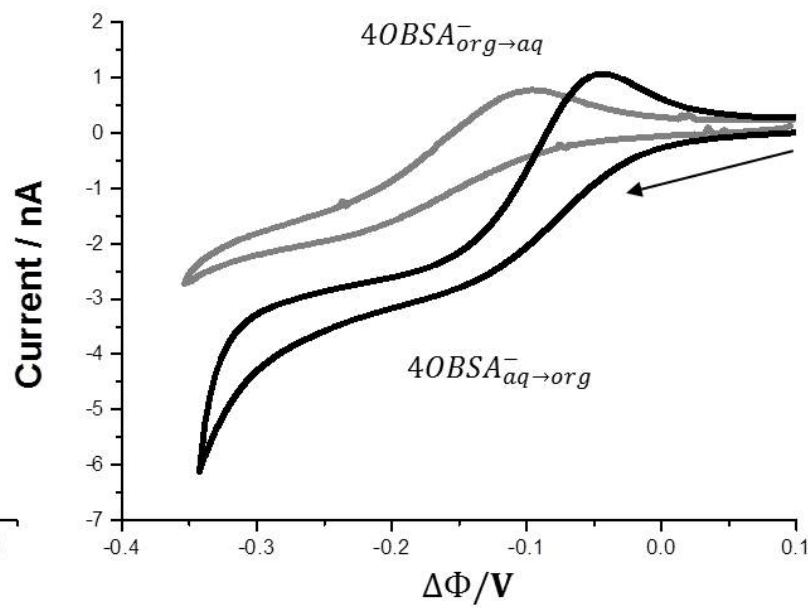

Figure 3. Cyclic voltammograms illustrating the transfer of interfacial active ions across the unmodified (black line) and modified (gray line) liquid/liquid interface; a) correspond to three different in size tetraalkylammonium cations, namely: $\mathrm{TMA}^{+}, \mathrm{TEA}^{+}$and $\mathrm{TBA}^{+}$whereas b) shows the transfer of anionic specie - 4OBSA ${ }^{-}$. Black, solid arrows indicate the direction of polarization during forward scan. The concentration of each ion was $56.8 \mu \mathrm{M}$, scan rate was $10 \mathrm{mV} \mathrm{s}^{-1}$.

The presence of the silica deposits has an impact on both the ion transfer potential and current intensity. For all four ions studied here, the presence of silica deposits at the $\mu$ ITIES makes the transfer more difficult as ion transfer potentials are shifted negatively by 22 for $\mathrm{TMA}^{+}, 26$ for $\mathrm{TEA}^{+}, 46 \mathrm{mV}$ for $\mathrm{TBA}^{+}$and by $50 \mathrm{mV}$ for $4 \mathrm{OBSA}^{-}$. We have estimated the difference of Gibbs Energy of transfer, $\delta \Delta G$, that this potential shift represented. $\delta \Delta G$ is the difference 
between the Gibbs energy of transfer before, $\Delta G_{b e f}$, and after modification, $\Delta G_{a f}$, (where $\Delta G=$ $\left.z F \Delta \Phi . \quad \delta \Delta G=\Delta G_{a f}-\Delta G_{b e f}=z F\left(\Delta \Phi_{a f}-\Delta \Phi_{b e f}\right)\right)$. The variation of Gibbs energy of ion transfer was plotted as a function of the ion hydrodynamic radius (Figure 4). For cations of the tetraalkylammonium series, the shift in Gibbs energy of transfer became larger as the hydrodynamic radius grew. This is to be expected as the diffusion of larger cations through the mesopores of the silica deposits might be more impeded than the smaller cations. The Gibbs energy of transfer for the anion $4 \mathrm{OBSA}^{-}$was also higher after modification than before indicating that the transfer had become even more difficult. The difference was higher than any of the cations tested, even larger than $\mathrm{TBA}^{+}$, whose hydrodynamic radius is almost twice bigger $\left(r_{h}\left(4 \mathrm{OBSA}^{-}\right)=0.30 \mathrm{~nm}\right.$ and $r_{h}\left(\mathrm{TBA}^{+}\right)=0.48 \mathrm{~nm}$ [40]). In spite of similar hydrodynamic radii, the behaviors of $\operatorname{TEA}^{+}\left(r_{h}=0.28 \mathrm{~nm}\right.$ [40]) and 4OBSA- were quite different with a shift of $2.5 \mathrm{~kJ} \mathrm{~mol}^{-1}$ for $\mathrm{TEA}^{+}$and $4.8 \mathrm{~kJ} \mathrm{~mol}^{-1}$ for $4 \mathrm{OBSA}^{-}$. A similar trend was observed for the ion transfer current with a drop caused by the interface modification: $59 \%$ for $4 \mathrm{OBSA}^{-}$and $48 \%$ for $\mathrm{TEA}^{+}$. This behavior can be attributed to electrostatic repulsion between negative net charge of silica surface (arising from the presence of deprotonated terminal $\mathrm{OH}$ groups located on the silica walls as the point of zero charge is 2 [41]) and anionic 4OBSA .

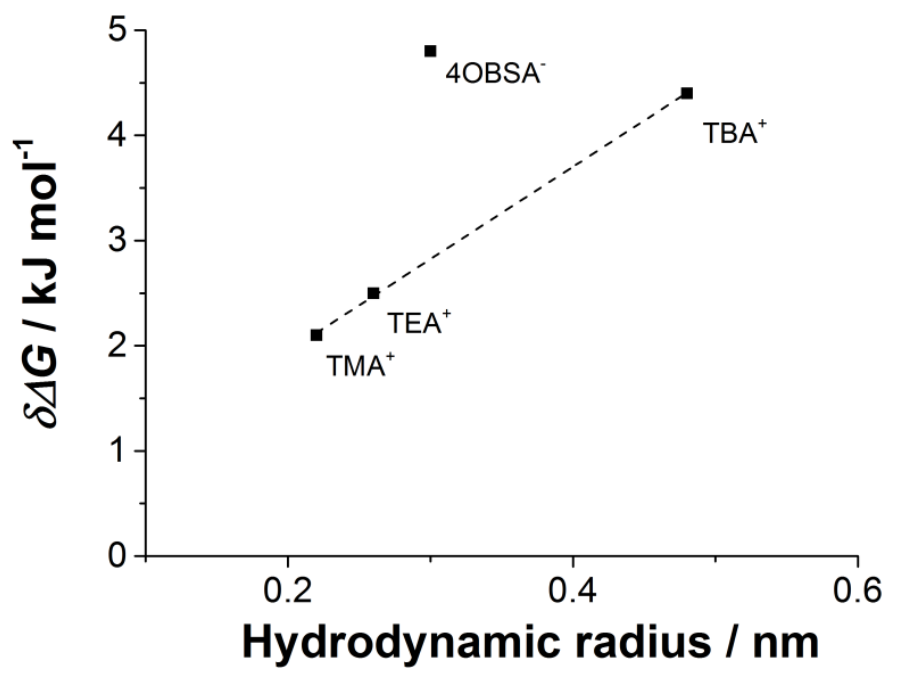

Figure 4. Variation of the difference of Gibbs energy of transfer as a function of the hydrodynamic radius of the ions studied. Hydrodynamic radii are given in Table 1.

\subsection{Ion transfer voltammetry of dendrimers before and after modification}

Dendrimers are the second family of species studied in this work. Large multi-charged species are giving complex electrochemical response at ITIES, which varies with the dendrimer 
generation. They can undergo either interfacial adsorption [7] or ion transfer $[7,8]$. Furthermore, PAMAM dendrimers at electrified liquid/liquid interface were employed as encapsulating agents for smaller porphyrin molecules [42] or molecular organic dyes [43]. Complex behavior of dendrimer-guest molecular association studied with cyclic voltammetry coupled with spectroscopic methods indicated that ion transfer reaction is accomplished with interfacial adsorption process - well pronounced by rapid current drop on the reverse peak [42]. Figure 5 shows the electrochemical behavior of PAMAM dendrimers G0 (Fig. 4 a) and G1 (Fig. 4 b) before (black lines) and after (gray lines) modification. The voltammograms are shown on the Galvani potential scale, based on the peak transfer of $\mathrm{Cl}^{-}$. Both PAMAM dendrimers $(28 \mu \mathrm{M})$ and the model ion $\mathrm{TEA}^{+}(42 \mu \mathrm{M})$ were initially present in the aqueous phase to facilitate the comparison. $\mathrm{CV}$ s from Figure 5A and 5B before modification had the same characteristics, independent of the generation of PAMAM dendrimer studied. A first sigmoidal wave rose at $+0.044 \mathrm{~V}$ corresponding to the non-diffusion limited transfer of $T E A_{a q \rightarrow o r g}^{+}$. The second sigmoidal wave originated from PAMAM $a q \rightarrow$ org transfer, which was partially masked by organic electrolyte anion transfer - $T P B C l_{o r g \rightarrow a q}^{-}$. On the reverse scan, back transfer of PAMAM dendrimers resulted in a peak response followed by diffusion limited back transfer of $T E A_{\text {org }}^{+} \rightarrow a q$. Prior to interfacial modification, both dendrimers (G0 and G1) underwent a simple ion transfer reaction, which is also the case at macroscopic ITIES [8]. Modification of the $\mu$ ITIES with silica led to the following results: (i) a lower forward current for both dendrimers, which was slightly more pronounced for PAMAM G1 (51\% of loss on the forward current as compared with a $29 \%$ loss on the forward current for PAMAM G0); (ii) a shift in forward and reverse transfer potentials towards more negative potentials, which was in contrast to the series of tetraalkylammonium cations. and (iii) the shape of back transfer peak for PAMAM G0 was unaffected after modification and hence a diffusionlimited peak was observed suggesting that the transfer current is due to an interfacial transfer reaction. The characteristics of PAMAM G1 behavior are more complex as the peak shape was changed. These phenomena (i, ii, and iii) may have two origins. First, on the forward scan, ion transfer can be affected by electrostatic interaction between positively-multi-charged dendritic molecules and negative net charge of silica (terminal $\mathrm{OH}$ groups inside the mesopores), which leads to charge screening and results in lower current. Second, the peak on the reverse scan (especially visible for PAMAM G1) is probably affected by adsorption process since additionally to the negative peak potential shift we have more rapid current drop and separation between forward and reverse signal increased from $64 \mathrm{mV}$ to $114 \mathrm{mV}$ (factors 
that are a fingerprint of macromolecules exhibiting adsorption behavior at ITIES) [7,42-44]. In the case of PAMAM G1 adsorption, facilitated transfer of organic electrolyte counter ion cannot be excluded and may give some additional portion of faradaic current on forward scan, as it was shown for proteins [12,13] and synthetic dendrimers [7] studied at ITIES.
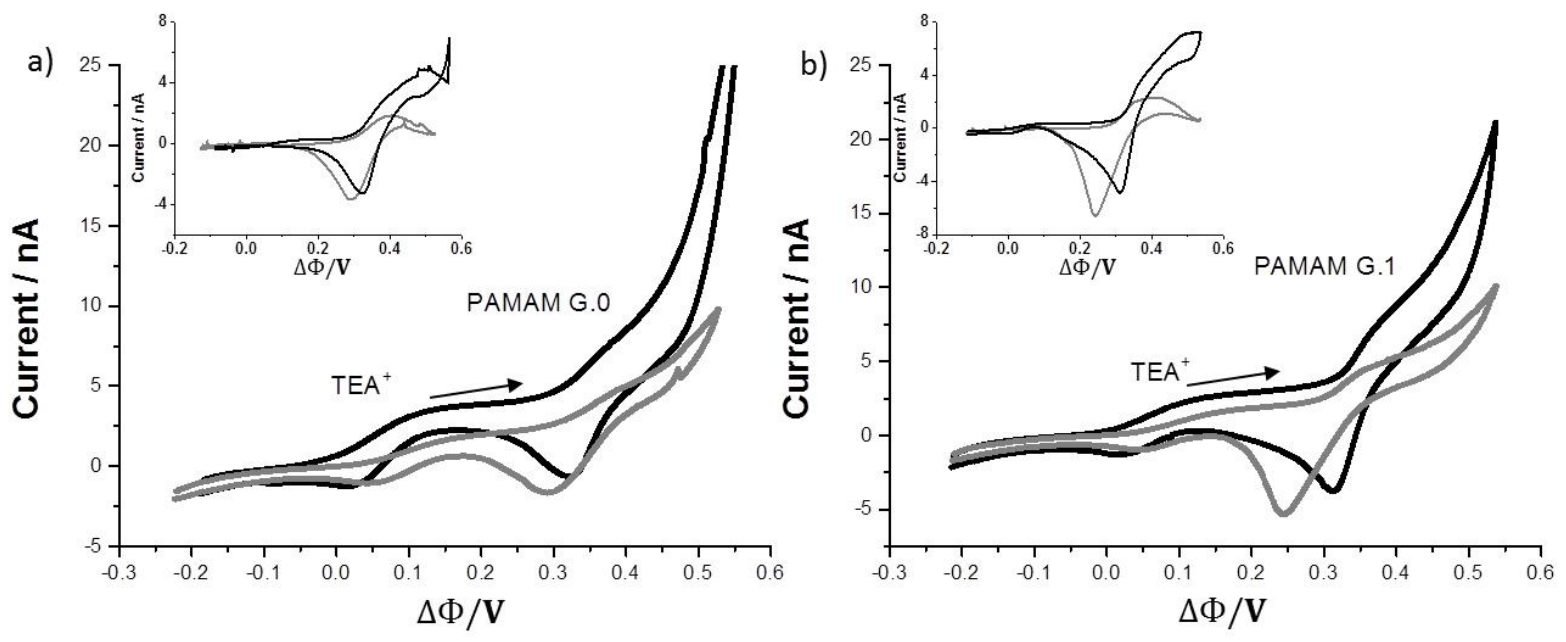

Figure 5. Cyclic voltammograms illustrating the transfer of a) PAMAM G0 and b) PAMAM G1 in the absence (black line) and presence (gray line) of silica deposits. The concentrations are $42 \mu \mathrm{M}$ and $28 \mu \mathrm{M}$ for $\mathrm{TEA}^{+}$and PAMAM respectively. Scan rate $=10 \mathrm{mV} \mathrm{s}^{-1}$. Black, solid arrows indicate the direction of polarization during forward scan. Insets: Backgroundsubtracted voltammograms.

3.4. Impact of $\mu$ ITIES modification on analytical parameters (sensitivity, limit of detection and apparent diffusion coefficients)

Figure 6 shows the CVs before (a) and after modification (b) and the calibration curves (c) for $\mathrm{TEA}^{+}(1), 4 \mathrm{OBSA}^{-}$(2) and PAMAM G1 (3). As already noticed, modification caused the decrease of the faradaic current. In our previous report [33], the modification of the interface resulted in an increase of the peak current and a shift of the transfer potentials towards more positive values. Such results were obtained with an initial TEOS concentration of $300 \mathrm{mM}$, which may induce different interfacial properties (including defects and cracks in the deposits). On the forward scan, the sigmoidal wave current increased linearly for the three tetraalkylammonium cations and $4 \mathrm{OBSA}^{-}$over the whole concentration range studied. This was observed for both before and after modification. The forward transfer current reached a plateau for the dendrimers calibration curves. The analytical parameters (sensitivity, limit of detection and apparent diffusion coefficients within the silica deposits) of silica modified $\mu$ ITIES were extracted from these calibration curves (Table 1). Based on equation (1), the 
limiting current for each of the concentration was calculated and was reported on Figure $6 \mathrm{c}$ as a solid line.

$$
i_{l i m}=4 n r z_{i} D F C_{i}
$$

where $n$ is the number of $\mu$ ITIES in the array $(n=30), r$ is the $\mu$ ITIES radius $(r=5 \mu \mathrm{m}), z_{i}$ is the charge of the species transferred, $F$ is the Faraday constant $\left(96485 \mathrm{C}^{\circ} \mathrm{mol}^{-1}\right)$ and $C_{i}$ is the concentration. Theoretical calibration curves in absence of silica deposits were fitted using eq. 1 with diffusion coefficient taken from other studies (exception was 4OBSA ${ }^{-}$for which diffusion coefficient was extracted from linear fit of experimental calibration curve (red dashed line in Fig. 6 2c). Berduque et al. have shown that the electrochemical behavior of PAMAM dendrimers G0 and G1, is characteristic of multiply charged species [8]. However, they demonstrated that the charge transferred is lower than the theoretical charge. There is a good correlation between the sensitivity calculated from Eq. (2) and the sensitivity measured experimentally before modification, $S_{0}$, for $\mathrm{TMA}^{+}, \mathrm{TEA}^{+}$, and to a lesser extent for $\mathrm{TBA}^{+}$and PAMAM G0 and G1.

a)

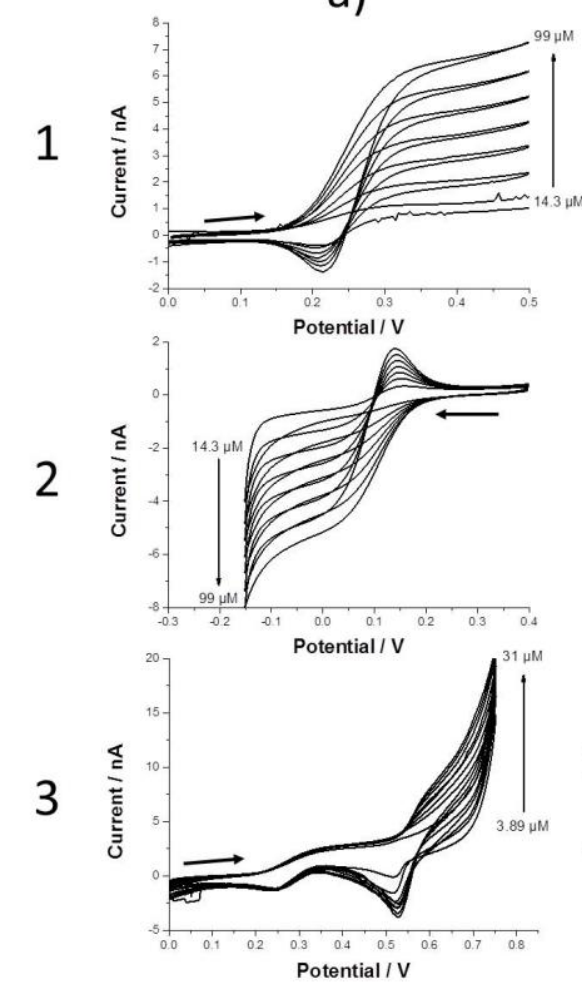

b)
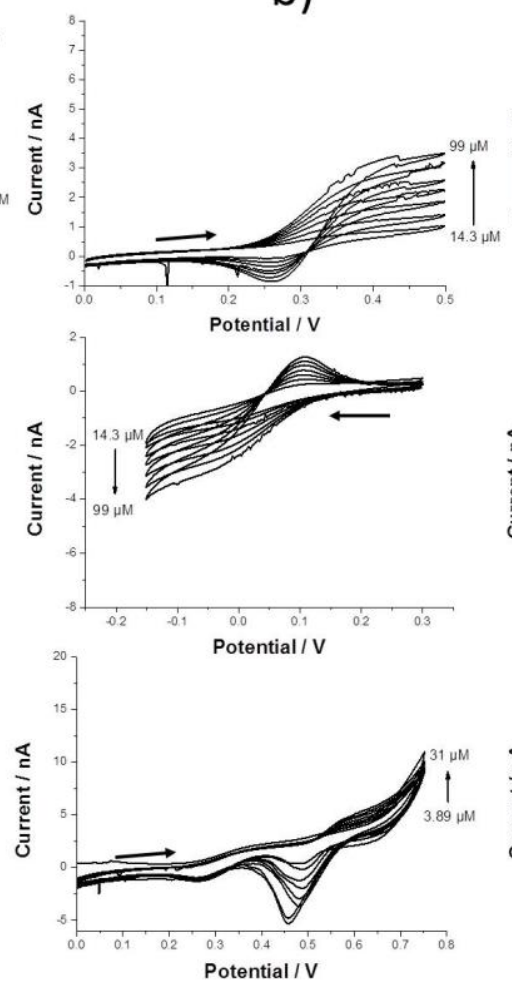

c)
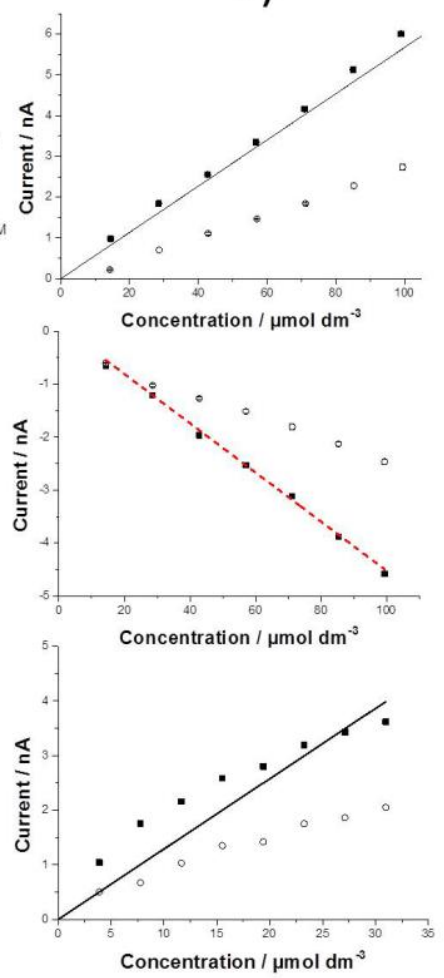

Figure 6. Data correspond to $\mathrm{TEA}^{+}$(row 1), 4OBSA- (row 2) and PAMAM G1 dendrimer (row 3). Cyclic voltammograms for different interfacial active ion concentrations recorded before modification are shown in column a, whereas their voltammetry behavior after modification is depicted in column b. Column c represents the calibration curves before 
modification (black squares), after modification (empty circles) and theoretical values calculated using equation (1) (solid lines). Error bars, however present are smaller than the size of the points. Arrows indicate the direction of polarization during forward scan. Scan rate was $10 \mathrm{mV} \mathrm{s}^{-1}$.

The impact of the interface modification on the sensitivity, $S$, is shown for the different ions studied as a function of the product of their charge, $z_{i}$, and their diffusion coefficient, $D_{i}$ (Figure 7). For single charge species, the impact of the interface modification on the sensitivity ratio $S / S_{0}$ ( $S_{0}$ is the sensitivity before modification) was lower for the smaller ion $\mathrm{TMA}^{+}$than for the larger $\mathrm{TBA}^{+}$. A similar trend was observed for dendrimers where the impact on the sensitivity ratio is greater for PAMAM G1 than for PAMAM G0. The sensitivity of the larger molecule (PAMAM G1) is more affected than the one of the smaller molecule (PAMAM G0). Nevertheless, the sensitivity ratio is higher for both these multiplycharged molecules than for single charge ions. This can be explained by stronger interactions between the negatively charged silica walls and the multiple charges of PAMAM dendrimers. The limit of detection (LOD) was calculated from the linear fit equation:

$$
L O D=\frac{3.3 S D}{s}
$$

where $S D$ is the standard deviation of the intercept and $S$ is the sensitivity. LODs for the ions studied before $\mu$ ITIES modification are in the $\mu \mathrm{M}$ range, with the exception of $\mathrm{TBA}^{+}$in the sub- $\mu \mathrm{M}$ range. The modification with mesoporous silica did not impact significantly as the LODs remained in the same range.

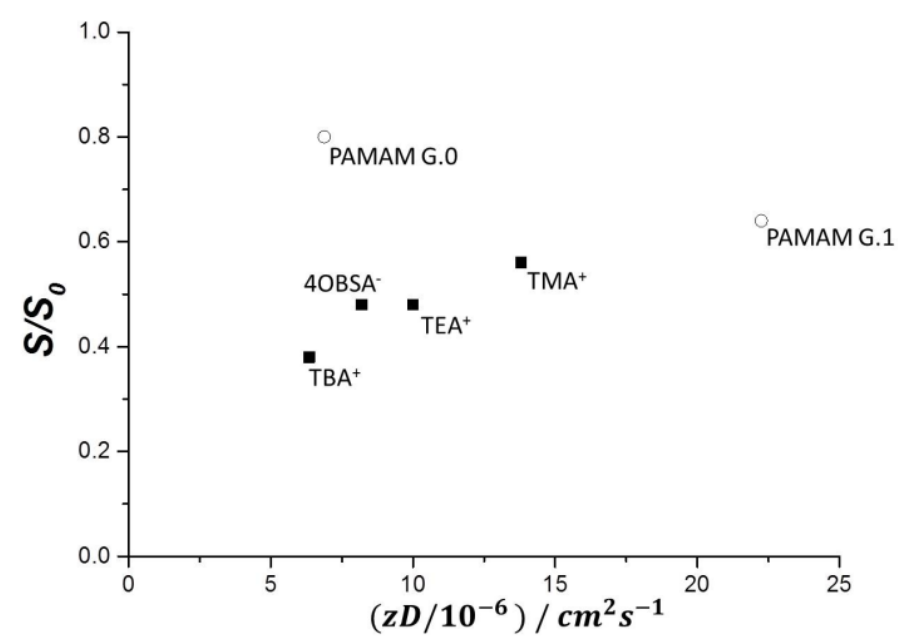

Figure 7. Sensitivity ratio, $S / S_{0}$, as a function of $z D$ for $4 \mathrm{OBSA}^{-}, \mathrm{TBA}^{+}$, $\mathrm{TEA}^{+}$and $\mathrm{TMA}^{+}$ PAMAM G0 and PAMAM G1. 
According to equation (1), the difference in sensitivity before and after modification can be explained by an impeded diffusion of charge species through mesoporous silica, leading to apparent diffusion coefficients, $D_{i}^{\prime}$, that are lower than the diffusion coefficients of species in the bulk solution. Since the aqueous side of the interface was modified, diffusion coefficient of species in the organic phase was not modified. From linear fit of calibration curves for modified $\mu$ ITIES using eq. 1 , we extracted $D_{i}^{\prime}$ for all species assuming that the $\mu$ ITIES radius remained unchanged in the presence of silica deposits (deposits are flat at the bottom and preferably filled with the aqueous phase). The $D_{i}^{\prime}$ calculated for all ions are shown in table 1 . $40 \%$ drop in diffusion coefficients for $\mathrm{TMA}^{+}$and $50 \%$ drop for $\mathrm{TEA}^{+}, \mathrm{TBA}^{+}$and $4 \mathrm{OBSA}^{-}$ were observed in the presence of silica deposits. These estimations are in agreement with previous studies. The diffusion coefficient of $\mathrm{TEA}^{+}$within zeolite Y modified ITIES (with the aperture diameter of $7.4 \AA$ ) was two order of magnitude lower than in aqueous phase [18]. TEM images showed that the mesopore dimensions of our material was significantly larger than zeolite $\mathrm{Y}$ (Figure 1) and hence the effect on $D_{i}^{\prime}$ is considerably smaller as on the diffusion coefficient through zeolite $Y$.

Table 1. Electroanalytical and structural data concerning interfacial active species used in this study.

\begin{tabular}{|c|c|c|c|c|c|c|c|c|c|}
\hline \multirow{2}{*}{$\begin{array}{c}\text { Ion } \\
\text { transferred }\end{array}$} & \multirow{2}{*}{$r_{h} / \mathbf{n m}$} & \multirow{2}{*}{$\begin{array}{c}\left(D_{i} / 1^{-6}\right) \\
/ \mathrm{cm}^{2} \cdot \mathrm{s}^{-1}\end{array}$} & \multirow{2}{*}{$\begin{array}{c}\left(D_{i}^{\prime} / 10^{-6}\right) \\
/ \mathrm{cm}^{2} \cdot \mathrm{s}^{-1}\end{array}$} & \multirow{2}{*}{$z_{i}$} & \multicolumn{3}{|c|}{ Sensitivity / $\mathbf{n A} \cdot \mathbf{m m o l}^{-1} \mathbf{d m}^{3}$} & \multicolumn{2}{|c|}{$\begin{array}{c}\text { LOD } * * \\
\mu \mathrm{mol} \mathbf{d m}^{-3}\end{array}$} \\
\hline & & & & & $S_{\text {theor. }}$ & $\begin{array}{c}S_{0} \\
\left(\mathbf{R}^{2}\right)\end{array}$ & $\begin{array}{c}S \\
\left(\mathbf{R}^{2}\right)\end{array}$ & $\mathbf{B M}$ & $\mathbf{A M}$ \\
\hline TMA $^{+}$ & $0.22[40]$ & $13.8[45]$ & 8.5 & +1 & 81.6 & $\begin{array}{c}87.4 \\
(>0.999)\end{array}$ & $\begin{array}{c}49.0 \\
(0.999)\end{array}$ & 1.91 & 0.82 \\
\hline TEA $^{+}$ & $0.26[40]$ & $\begin{array}{l}10.0 \pm \\
0.4[45]\end{array}$ & 5.0 & +1 & 56.7 & $\begin{array}{c}57.4 \\
(>0.999)\end{array}$ & $\begin{array}{c}28.8 \\
(0.998)\end{array}$ & 0.47 & 3.82 \\
\hline $\mathbf{T B A}^{+}$ & $0.48[40]$ & $\begin{array}{c}6.4 \pm \\
0.3[45]\end{array}$ & 3.1 & +1 & 36.6 & $\begin{array}{c}45.2 \\
(>0.999)\end{array}$ & $\begin{array}{c}17.4 \\
(0.997)\end{array}$ & 0.07 & 5.32 \\
\hline 40BSA ${ }^{-}$ & $0.30 *$ & $8.2 * *$ & 3.8 & -1 & $\mathrm{n} / \mathrm{a}$ & $\begin{array}{c}-46.4 \\
(0.998)\end{array}$ & $\begin{array}{c}-22.1 \\
(0.992)\end{array}$ & 3.88 & 2.78 \\
\hline PAMAM G0 & $0.70[46]$ & $3.4^{*}$ & 2.6 & $2[8]$ & 87.6 & 94.2 & 74.9 & 2.41 & 3.82 \\
\hline
\end{tabular}




\begin{tabular}{|l|c|c|c|c|c|c|c|c|c|}
\hline & & & & & & $(0.989)$ & $(0.986)$ & & \\
\hline PAMAM G1 & 0.55 [7] & $4.5[7]$ & 0.9 & $5[8]$ & 129 & $\begin{array}{c}91.6 \\
(0.961)\end{array}$ & $\begin{array}{c}58.6 \\
(0.977)\end{array}$ & 4.90 & 3.70 \\
\hline
\end{tabular}

$r_{h}$ is the hydrodynamic radius, $D_{i}$ is the aqueous diffusion coefficient, $D_{i}^{\prime}$ is the apparent diffusion coefficient determined experimentally, $z_{i}$ is the charge, $S_{\text {theor }}$ correspond to the theoretical sensitivity based on Eq. (1), $S_{0}$ correspond to the sensitivity at a bare $\mu$ ITIES and $S$ to the sensitivity at a modified $\mu$ ITIES, BM to before modification and AM to after modification. ${ }^{*}$ Calculated from the Stokes Einstein relationship, $r_{h}=k_{B} T 6 \pi \eta D$, where $\mathrm{k}_{\mathrm{B}}$ is the Boltzmann constant $\left(1.3807 \cdot 10^{-23} \mathrm{~m}^{2} \cdot \mathrm{kg} \cdot \mathrm{s}^{-2} \cdot \mathrm{K}^{-1}\right)$, T is the temperature $(293 \mathrm{~K}), \eta$ is the aqueous phase viscosity $(0.89 \mathrm{cP})$ and $\mathrm{D}$ is the diffusion coefficient $\left(\mathrm{cm} \mathrm{s} \mathrm{s}^{-1}\right)$. **Calculated from calibration curve fit based on equation describing limiting current at array of $\mu$ ITIES.

\section{Conclusion}

Arrays of $\mu$ ITIES were modified with silica deposits based on a sol-gel process with $\mathrm{CTA}^{+}$as a template and TEOS as a precursor species. Silica deposits were characterized by ion transfer voltammetry of six different analytes: $\mathrm{TBA}^{+}, \mathrm{TEA}^{+}, \mathrm{TMA}^{+}, 4 \mathrm{OBSA}^{-}$and PAMAM G0 and G1. The transfer peak currents observed for the transfer of all species were lower and the transfer peak potentials were shift depending on the nature of studied analyte. Increase in size of tetraalkylammonium cation has led to greater current drop and potential shift (from finely affected $\mathrm{TMA}^{+}$to clearly changed $\mathrm{TBA}^{+}$). In case of $4 \mathrm{OBSA}^{-}$both, current drop and $E_{1 / 2}$ shift were attributed to both size and charge effects. The electrochemical behavior of multipositively-charged dendrimers in the presence of silica deposits was attributed to electrostatic interaction with negatively charged silica net. Furthermore, $\mu$ ITIES modification affects differently the electroanalytical parameters (sensitivity, LOD and apparent diffusion coefficient) depending on the size of the species transferred, suggesting the future possibility of selective ion transfer using $\mu$ ITIES modified with functionalized mesoporous silica.

\section{Acknowledgment}

The authors are grateful to the Agence Nationale pour la Recherche (HYPERION Project ANR-14-CE04-0002) for financial support, to L. Salsi for SEM imaging and to J. Ghanbaja for TEM imaging. Tyndall National Institute (Cork, Ireland) is also acknowledged for supplying the silicon membranes. LP is grateful to Ecole Doctorale SESAMES for PhD funding.

\section{References}


[1] M.D. Scanlon, D.W.M. Arrigan, Electroanalysis 23 (2011) 1023.

[2] M. Rimboud, R.D. Hart, T. Becker, D.W.M. Arrigan, Analyst 136 (2011) 4674.

[3] M.D. Scanlon, G. Herzog, D.W.M. Arrigan, Anal. Chem. 80 (2008) 5743.

[4] T.J. Stockmann, A.-M. Montgomery, Z. Ding, J. Electroanal. Chem. 684 (2012) 6.

[5] C.J. Collins, D.W.M. Arrigan, Anal. Chem. 81 (2009) 2344.

[6] G. Herzog, V. Kam, A. Berduque, D.W.M. Arrigan, J. Agric. Food Chem. 56 (2008) 4304.

[7] G. Herzog, S. Flynn, C. Johnson, D.W.M. Arrigan, Anal. Chem. 84 (2012) 5693.

[8] A. Berduque, M.D. Scanlon, C.J. Collins, D.W.M. Arrigan, Langmuir 23 (2007) 7356.

[9] M.A. González-Fuentes, J. Manríquez, R. Antaño-López, L.A. Godínez, Electrochem. Commun. 12 (2010) 137.

[10] L. Zhang, Y. Kitazumi, T. Kakiuchi, Langmuir 27 (2011) 13037.

[11] J.S. Riva, D.M. Beltramo, L.M. Yudi, Electrochim. Acta 115 (2014) 370.

[12] G. Herzog, V. Kam, D.W.M. Arrigan, Electrochim. Acta 53 (2008) 7204.

[13] M.D. Scanlon, J. Strutwolf, D.W.M. Arrigan, Phys. Chem. Chem. Phys. 12 (2010) 10040.

[14] D.W.M. Arrigan, Annu. Rep. Prog. Chem., Sect C Phys. Chem. 109 (2013) 167.

[15] D.W.M. Arrigan, Anal. Lett. 41 (2008) 3233.

[16] D.W.M. Arrigan, G. Herzog, M.D. Scanlon, J. Strutwolf, in:, A.J. Bard, C.G. Zoski (Eds.), Electroanal. Chem. Vol. 25, CRC Press, Boca Raton, 2013, pp. 105-178.

[17] D. Homolka, L.Q. Hung, A. Hofmanova, M.W. Khalil, J. Koryta, V. Mareček, Z. Samec, S.K. Sen, P. Vanysek, J. Weber, M. Brezina, M. Janda, I. Stibor, Anal. Chem. 52 (1980) 1606.

[18] S. Senthilkumar, R.A.W. Dryfe, R. Saraswathi, Langmuir 23 (2007) 3455.

[19] W. Kutner, J. Wang, M. L’Her, R.P. Buck, Pure Appl. Chem. 70 (1998) 1301.

[20] A. Walcarius, Chem. Soc. Rev. 42 (2013) 4098.

[21] Y. Wan, D. Zhao, Chem. Rev. 107 (2007) 2821.

[22] N. Vilà, J. Ghanbaja, E. Aubert, A. Walcarius, Angewan. Chem. Int. Ed. 53 (2014) 2945. 
[23] A. Goux, M. Etienne, E. Aubert, C. Lecomte, J. Ghanbaja, A. Walcarius, Chem. Mater. 21 (2009) 731.

[24] A. Walcarius, E. Sibottier, M. Etienne, J. Ghanbaja, Nat. Mater. 6 (2007) 602.

[25] J.S. Beck, K.D. Schmitt, J.B. Higgins, J.L. Schlenkert, J. Am. Chem. Soc. 114 (1992) 10834.

[26] S. Hudson, J. Cooney, E. Magner, Angewan. Chem. Int. Ed. 47 (2008) 8582.

[27] P. Kumar, V. V. Guliants, Microporous Mesoporous Mater. 132 (2010) 1.

[28] H. Yang, D. Zhao, J. Mater. Chem. (2005).

[29] B.G. Trewyn, S. Giri, I.I. Slowing, V.S.-Y. Lin, Chem. Commun. (2007) 3236.

[30] A. Walcarius, Anal. Bioanal. Chem. 396 (2010) 261.

[31] A. Walcarius, Electroanalysis 20 (2008) 711.

[32] M. Etienne, A. Goux, E. Sibottier, A. Walcarius, J. Nanosci. Nanotechno. 9 (2009) 2398.

[33] L. Poltorak, G. Herzog, A. Walcarius, Electrochem. Commun. 37 (2013) 76.

[34] L. Poltorak, G. Herzog, A. Walcarius, Langmuir 30 (2014) 11453.

[35] L. Poltorak, M. Dossot, G. Herzog, A. Walcarius, Phys. Chem. Chem. Phys. 16 (2014) 26955.

[36] R. Zazpe, C. Hibert, Y.H. Lanyon, D.W.M. Arrigan, (2007) 1732.

[37] A.J. Olaya, M.A. Méndez, F. Cortes-Salazar, H.H. Girault, J. Electroanal. Chem. 644 (2010) 60 .

[38] A. Sabela, V. Marecek, Z. Samec, R. Fuoco, Electrochim. Acta 37 (1992) 231.

[39] Y. Shao, A.A. Stewart, H.H. Girault, J. Chem. Soc. Faraday Trans. 87 (1991) 2593.

[40] R. Ishimatsu, J. Kim, P. Jing, C.C. Striemer, D.Z. Fang, P.M. Fauchet, J.L. McGrath, S. Amemiya, Anal. Chem. 82 (2010) 7127.

[41] J. Persello, in:, E. Papirer (Ed.), Adsorpt. Silica Surfaces, Surf. Sci. Ser. Vol. 90, Marcel Dekker, New York, 2000, pp. 317-318.

[42] H. Sakae, H. Nagatani, K. Morita, H. Imura, Langmuir 30 (2014) 937.

[43] H. Nagatani, T. Sakamoto, T. Torikai, T. Sagara, Langmuir 26 (2010) 17686.

[44] H. Nagatani, T. Ueno, T. Sagara, Electrochim. Acta 53 (2008) 6428. 
[45] T. Hinoue, E. Ikeda, S. Watariguchi, Y. Kibune, Anal. Chem. 79 (2007) 291.

[46] B. Devarakonda, R.A. Hill, M.M. de Villiers, Int. J. Pharm. 284 (2004) 133. 